\title{
Isolation and Characterization of Avirulence Genes in Magnaporthe oryzae
}

\author{
MUI SIE JEE ${ }^{1}$, LEONARD WHYE KIT LIM ${ }^{1}$, MARTINA AZELIN DIRUM ${ }^{1}$, SARA ILIA \\ CHE HASHIM ${ }^{1}$, MUHAMMAD SHAFIQ MASRI ${ }^{1}$, HUI YING TAN ${ }^{1}$, LEE SAN LAI $^{2}$, \\ FREDDY KUOK SAN YEO ${ }^{1} \&$ HUNG HUI CHUNG*1
}

\author{
${ }^{1}$ Faculty of Resource Science and Technology, Universiti Malaysia Sarawak, 94300 Kota Samarahan, \\ Sarawak, Malaysia, ${ }^{2}$ Department of Plant Pathology, Agriculture Research Centre, P.O.Box 977, 93720 \\ Kuching, Sarawak, Malaysia \\ *Corresponding author: hhchung@unimas.my
}

\begin{abstract}
Magnaporthe oryzae is a fungal pathogen contributing to rice blast diseases globally via their Avr (avirulence) gene. Although the occurrence of $M$. oryzae has been reported in Sarawak since several decades ago, however, none has focused specifically on $A v r$ genes, which confer resistance against pathogen-associated molecular pattern-triggered immunity (PTI) in host. The objective of this study is to isolate Avr genes from M. oryzae 7' (a Sarawak isolate) that may contribute to susceptibility of rice towards diseases. In this study, AvrPiz-t, AVR-Pik, $A v r-P i 54$, and $A V R$-Pital genes were isolated via PCR and cloning approaches. The genes were then compared with set of similar genes from related isolates derived from NCBI. Results revealed that all eight $A v r$ genes (including four other global isolates) shared similar N-myristoylation site and a novel motif. 3D modeling revealed similar $\beta$-sandwich structure in $A v r P i z-t$ and $A V R$-Pik despite sequence dissimilarities. In conclusion, it is confirmed of the presence of these genes in the Sarawak (M. oryzae) isolate. This study implies that Sarawak isolate may confer similar avirulence properties as their counterparts worldwide. Further R/Avr gene-for-gene relationship studies may aid in strategic control of rice blast diseases in future.
\end{abstract}

Keywords: Plant disease, rice blast, Sarawak, Magnaporthe oryzae

\section{INTRODUCTION}

Magnaporthe oryzae is a rice blast pathogen causing major harvest loss globally. It belongs to hemibiotrophic fungus which grows biotrophically on living plant tissue during initial life cycle and subsequently into necrotrophic mode causing the death of infected plant tissues (Horbach et al., 2011). It is known that $M$. oryzae encodes a variety of effector molecules to confer virulence (Li et al., 2009). Effectors deployed by pathogens interfere with PTI (pathogen-associated molecular patterntriggered immunity), given that the PTI is overcome, the effectors will be recognized by specific $\mathrm{R}$ genes and followed by the action of ETI (effector-triggered immunity). The recognized effectors are described as AVR (avirulence) protein (Jones \& Dangl, 2006). Hence, ETI brings about the development of disease resistance and often causes HR (hypersensitive response) at the site of infection. HR is a rapid and localized tissue necrosis at the penetration site and involves transcriptional activation of various defense genes of the plant which subsequently avoid further spread of pathogen through the plant tissue (Lamb, 1994; Joosten et al., 1997; Agrios, 2005). To date, several effector proteins encoded by $A v r$ genes from $M$. oryzae have been cloned molecularly, namely PWL2 (Sweigard et al., 1995), AVR-Pita (Orbach et al., 2000), AVRPia (Miki et al., 2009; Yoshida et al., 2009), AVR-Pii (Yoshida et al., 2009), AVR-Pik (Yoshida et al., 2009), AvrPiz-t (Li et al., 2009), AVR1-CO39 (Ribot et al., 2013), AvrPi9 (Wu et al., 2015), AvrPib (Zhang et al., 2015), and Avr-Pi54 (Ray et al., 2016).

Malaysia is granted with temperature regime and rainfall distribution that favour year round rice cultivation, even if in the conditions of rainfed (Food and Agriculture Organization of the United Nations, 2002). According to Valera \& Lee (2016), Malaysia achieved $63 \%$ self-sufficiency in rice production and relied the rest of it on rice import to compensate domestic production. With the ever increasing domestic demand in the country, ensuring a sustainable food supply is vital for the continuous development of the nation. 
Several studies have been done on the blast resistance gene ( $R$ gene) in local rice varieties previously, however report on $A v r$ gene in local $M$. oryzae which functions in complement with resistance genes is lacking (Fatah et al., 2014; Tanweer et al., 2015). This reflected an urge to bridge the knowledge gap in order to develop a more comprehensive and novel strategy in rice blast control. In this study, focus would be on preliminary finding of $A v r$ genes from $M$. oryzae 7' isolate of Sarawak which has never been investigated.

\section{MATERIALS AND METHODS}

\section{Fungal Culture and Species Verification}

Pure strain of $M$. oryzae 7' from Sarawak isolates was provided by Agriculture Research Centre Semenggok and cultured on oatmeal agar (instant oatmeal). The cultures were incubated at $28 \pm 0.5^{\circ} \mathrm{C}$ at dark for 5 days and were grown under continuous light for consecutive days. Fungal mycelia were harvested by using micropipette tip and subjected to direct PCR for species verification using ITS1/ITS4 universal primer pair with T100 ${ }^{\mathrm{TM}}$ Thermal Cycler (Bio-Rad Laboratories, USA).

Direct PCR was carried out in a $20 \mu \mathrm{l}$ reaction volume per PCR tube containing $10 \mathrm{x}$ EasyTaq $^{\circledR}$ Buffer (with $\mathrm{Mg}^{2+}$ ), $2.5 \mathrm{mM}$ dNTPs, EasyTaq $^{\circledR}$ DNA Polymerase, $10 \mu \mathrm{M}$ ITS1 forward primer, $10 \mu \mathrm{M}$ ITS4 reverse primer, and $\mathrm{ddH}_{2} \mathrm{O}$ by referring to protocol as suggested by manufacturer of EasyTaq ${ }^{\circledR}$ DNA
Polymerase (TransGen Biotech, China) in the following parameter: initial denaturation of $94^{\circ} \mathrm{C}$ for 2 minutes, 35 cycles of $94^{\circ} \mathrm{C}$ for 30 seconds, $57^{\circ} \mathrm{C}$ for 30 seconds, $72^{\circ} \mathrm{C}$ for 1 minute, and a final extension of $72^{\circ} \mathrm{C}$ for 5 minutes. PCR product was run on a $1.5 \%$ agarose gel and visualized under UV transilluminator for band detection. Single, specific band containing gene fragment of interest was excised and subjected to purification using Wizard ${ }^{\circledR}$ SV Gel and PCR Clean-Up System (Promega, US).

Purified PCR product was then sent to First BASE Laboratories (Malaysia) for sequencing. The sequence received from First BASE Laboratories was checked by using MEGA 6 (Version 6.0) (Tamura et al., 2013). The identity of the gene sequence was analyzed by BLASTn (Version 2.3.1+) (Altschul et al., 1997).

\section{Primer Design}

Nucleotide sequences of AvrPiz-t, AVR-Pik, Avr-Pi54, and AVR-Pital genes from other global isolates were retrieved from database of NCBI Genbank. From the identified conserved gene region using Clustal Omega (Version 1.2.1) (Sievers et al., 2011), forward and reverse primer pair was designed by using Primer3Plus (Untergasser et al., 2007) and Oligonucleotide Properties Calculator (Kibbe, 2007). Primer sequences were sent to First BASE Laboratories for subsequent synthesis. Details on the primer sequence were shown in Table 1.

Table 1. List of primers used and their details.

\begin{tabular}{|c|c|c|c|c|}
\hline Target Gene & Primer & Primer Sequence (5'-3') & $\begin{array}{l}\text { Optimized } \mathrm{T}_{\mathrm{a}} \\
\left({ }^{\circ} \mathrm{C}\right)\end{array}$ & $\begin{array}{l}\text { Amplicon Size } \\
\text { (bp) }\end{array}$ \\
\hline \multirow{2}{*}{$\begin{array}{l}\text { ITS1 region, } \\
5.8 \mathrm{~S} \text {, and ITS2 } \\
\text { region }\end{array}$} & ITS1 & TCCGTAGGTGAACCTGCGG & \multirow[b]{2}{*}{57.0} & \multirow[b]{2}{*}{$\sim 497$} \\
\hline & ITS4 & TCCTCCGCTTATTGATATGC & & \\
\hline \multirow[b]{2}{*}{ AvrPiz- $t$} & MOPIZTF1 & ATGCAGTTCTCAACCATCATCA & \multirow[b]{2}{*}{60.7} & \multirow[b]{2}{*}{327} \\
\hline & MOPIZTR1 & CTATTGGCGCTGAGCCTGA & & \\
\hline \multirow[b]{2}{*}{$A V R-P i k$} & MOPIKF1 & ATGCGTGTTACCACTTTTAACA & \multirow[b]{2}{*}{58.6} & \multirow[b]{2}{*}{342} \\
\hline & MOPIKR1 & TTAAAAGCCGGGCCTTTT & & \\
\hline \multirow[b]{2}{*}{ Avr-Pi54 } & MOPI54F1 & ATGCAGTTCACCGCCACCAT & \multirow[b]{2}{*}{59.5} & \multirow[b]{2}{*}{462} \\
\hline & MOPI54R1 & CTAGCAGCCATAGGTGAGGA & & \\
\hline \multirow[b]{2}{*}{ AVR-Pital } & MOPITAF1 & ATGCTTTTTTATTCATTGTTATTTT & \multirow[b]{2}{*}{58.6} & \multirow{2}{*}{884} \\
\hline & MOPITAR1 & TTAACAATWTTTATAACGTGCACAT & & \\
\hline
\end{tabular}




\section{PCR Optimization and Gene Amplification}

EasyTaq $^{\circledR}$ DNA Polymerase (TransGen Biotech, China) was used for gene amplification, protocol and components of reaction was slightly adjusted from Martin \& Rygiewicz (2005). Gene-specific primer pairs were used and optimized separately in gradient PCR by using $\mathrm{T} 100^{\mathrm{TM}}$ Thermal Cycler (Bio-Rad Laboratories, USA) (refer to Table 1). Positive control (ITS1/ITS4 primer pair) and negative control were carried out in parallel. Samples from PCR reaction were run on $2 \%$ agarose gel and visualized under UV transilluminator.

\section{Cloning of $A v r$ Genes}

Single, specific band containing gene fragment of interest for each $A v r$ gene was excised, and subjected to purification using Wizard ${ }^{\circledR}$ SV Gel and PCR Clean-Up System (Promega, USA) according to the manufacturer's protocol with slight modification. Purified PCR product was ligated into pGEM $^{\circledR}$-T Easy Vector (Promega, USA) and was transformed into E. coli XL1Blue competent cell. Identification of recombinant bacterial colonies was carried out by blue/white screening followed by elimination of false positive colonies by secondary blue/white screening. Positive colonies were subjected to colony PCR for direct identification of vectors containing desired insert and purified by using PureYield ${ }^{\mathrm{TM}}$ Plasmid Miniprep System (Promega, USA). Verification of proper gene insertion into the multiple cloning site was performed by restriction digestion using FastDigest enzyme, NotI (Promega, USA). Purified plasmids each containing desired $A v r$ genes were sent for sequencing.

\section{DNA Sequencing and Data Analysis}

The sequence file of AvrPiz-t, AVR-Pik, Avr$P i 54$, and AVR-Pita 1 genes was accessed with MEGA 6 (Version 6.0) (Tamura et al., 2013). Open reading frame (ORF) of the gene was identified and the nucleotide sequence of vector was removed. The gene sequence was analyzed by BLASTn (Version 2.3.1+) (Altschul et al., 1997). Then, the nucleotide sequences were translated into protein sequence by using ExPASy translate tool (Artimo et al., 2012) for further sequence characterization. The nucleotide translated protein sequence was analyzed by BLASTp (Version 2.3.1+) (Altschul et al., 1997) for similarity search. On the other hand, the protein sequences of $A v r P i 9$ (AIS23643.1), AVR-Pia (BAH59484.1), AVR-Pii (BAH59485.1) and AvrPib (AKO62639.1) from $M$. oryzae of global isolates, each encoding for AVR type effector proteins were retrieved from GenBank database. ProtParam server (Gasteiger et al., 2005) was used for physico-chemical analyses such as length of amino acid residues, molecular weight, and theoretical pI. Subcellular localization was predicted by CELLO server (Version 2.5) (Yu et al., 2006). SignalP4.1 (Petersen et al., 2011) was used to identify signal peptide cleavage site. Apart from that, the presence of domains and motifs were detected through ScanProsite online software (de Castro et al., 2006), Interpro Scan 5 online software (Jones et al., 2014), Conserved Domain Database server (Marchler-Bauer et al., 2015), and MEME online software (Bailey \& Elkan, 1994). Sequence variation in a novel motif detected was analyzed for conservation by using Clustal Omega (Version 1.2.1) (Sievers et al., 2011). Three-dimensional protein modeling was performed by using Phyre2 (Kelley et al., 2015), Jmol (http://www.jmol.org/) and ProFunc (Laskowski et al., 2005). Validation of modeled proteins was carried out by RAMPAGE for Ramachandran Plot analysis (Lovell et al., 2002). Then, Dali server (Holm \& Laakso, 2016) was used to identify the structural neighbours.

\section{RESULTS}

\section{Fungal culture and species verification}

In order to verify the identity of fungus cultured, molecular characterization by direct sequencing appeared as a precise approach. Universal primer pair ITS1/ITS4 was used for the amplification of ITS1 region, 5.8S rRNA (ribosomal ribonucleic acid) gene, and ITS2 region from $M$. oryzae 7'. At an annealing temperature of $57^{\circ} \mathrm{C}$, a single, specific band with an estimated size that range between 500 bp and $600 \mathrm{bp}$ was obtained. After purification and sequencing, BLASTn sequence similarity 
search verified the identity of fungal culture as M. oryzae. M. oryzae 7' shared a total similarity to that of M. oryzae MG1-1 (KJ766301.1) with a low E-value of 0.0 representing this result is highly significant.

\section{Primer design for isolation of $\boldsymbol{A v r}$ genes}

Four Avr genes were isolated from M. oryzae 7' isolate are, AvrPiz- $t$ (KX459419), AVR-Pik (KX459420), Avr-Pi54 (KY441415), and AVRPital (KY441414), each encoding for effector protein that interacts with respective racespecific resistance protein in host rice plant. A number of replicates of each gene were sent for sequencing, and a consistent result was obtained. BLASTn revealed these four isolated $A v r$ genes having a $99 \%$ similarity to previously deposited data from other global $M$. oryzae populations. This has proven the presence of these four Avr genes in M. oryzae 7' of Sarawak isolates. Similarly, BLASTp sequence similarity search using nucleotide translated protein sequence unveiled high degree of similarities to available database. Three of the Avr genes (AvrPiz-t, AVR-Pik, and $A v r-P i 54)$ isolated were intronless whereas AVR-Pital contains three segments of introns and was removed manually. Each of the isolated gene sequence having a complete open reading frame encoding from start codon until stop codon, with size of 108 aa, 112 aa, 153 aa, and 224 aa with respect to AvrPiz-t, AVR-Pik, Avr-Pi54, and AVR-Pital.

\section{Characterization of Avr genes}

In order to further investigate the functional elements found in $A v r$ genes, four other $A v r$ gene sequences from $M$. oryzae of global isolates carrying out similar function has been retrieved from Genbank for further characterizations. From Table 2, it is known that each $A v r$ genes encoded for a relatively small-sized protein molecules, where all of them except Avr-Pital, were predicted to be secreted extracellularly, of which three of them Avr-Pi54, AVR-Pia, and AvrPib has other additional sites of subcellular localization in plasma membrane, mitochondrial, periplasmic, and cytoplasmic region; whereas AVR-Pital was an exception predicted to be localized on plasma membrane. Information on the subcellular localization of these effector proteins would perhaps provide some clue on their functions within the highly compartmentalized eukaryotic cells. Result generated from SignalP4.1 reveals the presence of signal peptide and the absence of transmembrane segment in all of the analyzed sequences.

Table 2. Physico-chemical properties and subcellular localization of effector proteins encoded by avirulence genes.

\begin{tabular}{|c|c|c|c|c|c|c|}
\hline \multirow{2}{*}{$\begin{array}{l}\text { Effector } \\
\text { protein }\end{array}$} & \multirow{2}{*}{$\begin{array}{l}\text { Accession } \\
\text { number }\end{array}$} & \multicolumn{2}{|c|}{$\begin{array}{l}\text { Number of amino } \\
\text { acid residues }\end{array}$} & \multirow{2}{*}{$\begin{array}{l}\text { Molecular } \\
\text { weight (kDa) }\end{array}$} & \multirow{2}{*}{$\begin{array}{c}\text { Theoretical } \\
\text { pI }\end{array}$} & \multirow{2}{*}{$\begin{array}{l}\text { Subcellular } \\
\text { localization }\end{array}$} \\
\hline & & $\begin{array}{l}\text { Signal } \\
\text { peptide }\end{array}$ & $\begin{array}{l}\text { Mature } \\
\text { chain }\end{array}$ & & & \\
\hline AvrPiz-t & KX459419 & $1-18$ & $19-108$ & 11.70 & 9.17 & Extracellular \\
\hline AVR-Pik & KX459420 & $1-21$ & $22-113$ & 12.94 & 8.49 & Extracellular \\
\hline Avr-Pi54 & KY441415 & $1-19$ & $20-153$ & 15.80 & 6.52 & $\begin{array}{c}\text { Extracellular Plasma } \\
\text { Membrane }\end{array}$ \\
\hline AVR-Pital & KY441414 & $1-17$ & $18-224$ & 26.00 & 6.09 & Plasma Membrane \\
\hline AvrPi9 & AIS23643.1 & $1-18$ & $19-91$ & 9.56 & 6.94 & Extracellular \\
\hline AVR-Pia & BAH59484.1 & $1-19$ & $20-85$ & 9.43 & 7.82 & $\begin{array}{l}\text { Extracellular } \\
\text { Mitochondrial }\end{array}$ \\
\hline$A V R-P i i$ & BAH59485.1 & $1-19$ & $20-70$ & 7.50 & 6.00 & Extracellular \\
\hline AvrPib & AKO62639.1 & $1-22$ & $23-74$ & 8.12 & 9.22 & $\begin{array}{l}\text { Periplasmic } \\
\text { Cytoplasmic } \\
\text { Extracellular }\end{array}$ \\
\hline
\end{tabular}


Of all the eight genes, only AVR-Pital contains a M35 deuterolysin like domain and is detected to be under M35 like superfamily. On the other hand, there is some high frequency motif such as $\mathrm{N}$-myristoylation site, protein kinase $\mathrm{C}$ phosphorylation site, casein kinase II phosphorylation site, N-glycosylation site, and amidation site. As shown in Table 3, all effector proteins having the common presence $\mathrm{N}$-myristoylation motif on their protein sequences.

Through multiple sequence alignment, these eight gene sequences was not found to share any significant sequence similarity to each other (data not shown). MEME server has however detected the presence of a novel motif across four genes (AvrPiz-t, AvrPi9, AVR-Pia, and $A V R-P i i)$ out of the analyzed eight genes (AvrPiz-t, AVR-Pik, Avr-Pi54, AVR-Pital, AvrPi9, AVR-Pia, AVR-Pii, and AvrPib) (refer to Figure 1). The motif consists of six amino acid residues at regions coding for signal peptide supported with an e-value of 3.9e-004.

Apart from that, structures of the four locally isolated Avr genes (AvrPiz-t, AVR-Pik, AvrPi54, and AVR-Pital) were in silico modeled and validated using Ramachandran plots (Figure 2 and Table 4). It is shown that $>90 \%$ of residues in models of AvrPiz-t, Avr-Pik, and $A V R$-Pital were in the favored and allowed regions and thus indicates for an overall good quality of modeled proteins. From the modeled 3D structures, AvrPiz-t and Avr-Pik contains antiparallel $\beta$-sheets that form a $\beta$-sandwich structure containing 6 strands. This is consistent with previous studies carried out by Maqbool et al. (2015) and Zhang et al. (2013). The significance in structural relationship between AvrPiz-t and AVR-Pik has been presented by the Dali Z-score of 3.7 in this study using locally isolated $A v r$ genes. From the structural neighbours as indicated by Dali server, there are common structural neighbours shared between AvrPiz-t and AVR-Pik (Table 4). Structural neighbours of AvrPiz-t and AVR-Pik (PDB ID: 2MM0-A, 2MM2-A , 5A6W-C, 2MYV-A , 2LW6-A , 2MYW-A) having the common $\beta$-sandwich structure (de Guillen et al., 2015; Maqbool et al., 2015; Nyarko et al., 2014; Zhang et al., 2013).

In contrary, the modeled AVR-Pital is relatively helix-rich based on the predicted secondary structure as compared to other $A v r$ genes isolated. The structural neighbours of AVR-Pital (2X3C-A, 1G12-A, 1EB6-A) are metalloendopeptidase. This could be due to the properties of AVR-Pital as a member of M35 family containing motif encoded for zinc protease. Whereas the lack of support in Ramachandran plots and the absence of structural neighbour in $A v r-P i 54$ could be due to the characteristics of $A v r-P i 54$ as a twilightzone proteins that complicates the modeling of the protein. On the other hand, the 3D structure of AVR-Pital and Avr-Pi54 do not display significant structural similarities to that of AvrPiz-t and Avr-Pik.

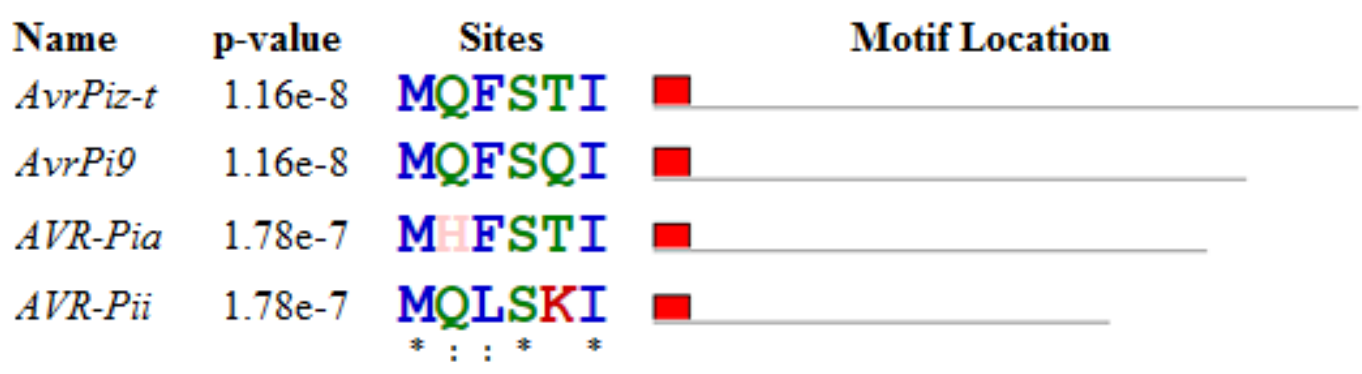

Figure 1. Location of novel motif detected on AvrPiz-t, AvrPi9, AVR-Pia, and AVR-Pii. (Asterisk (*) represents residue is fully conserved, whereas colon (:) represents residue is conserved in similar properties). 


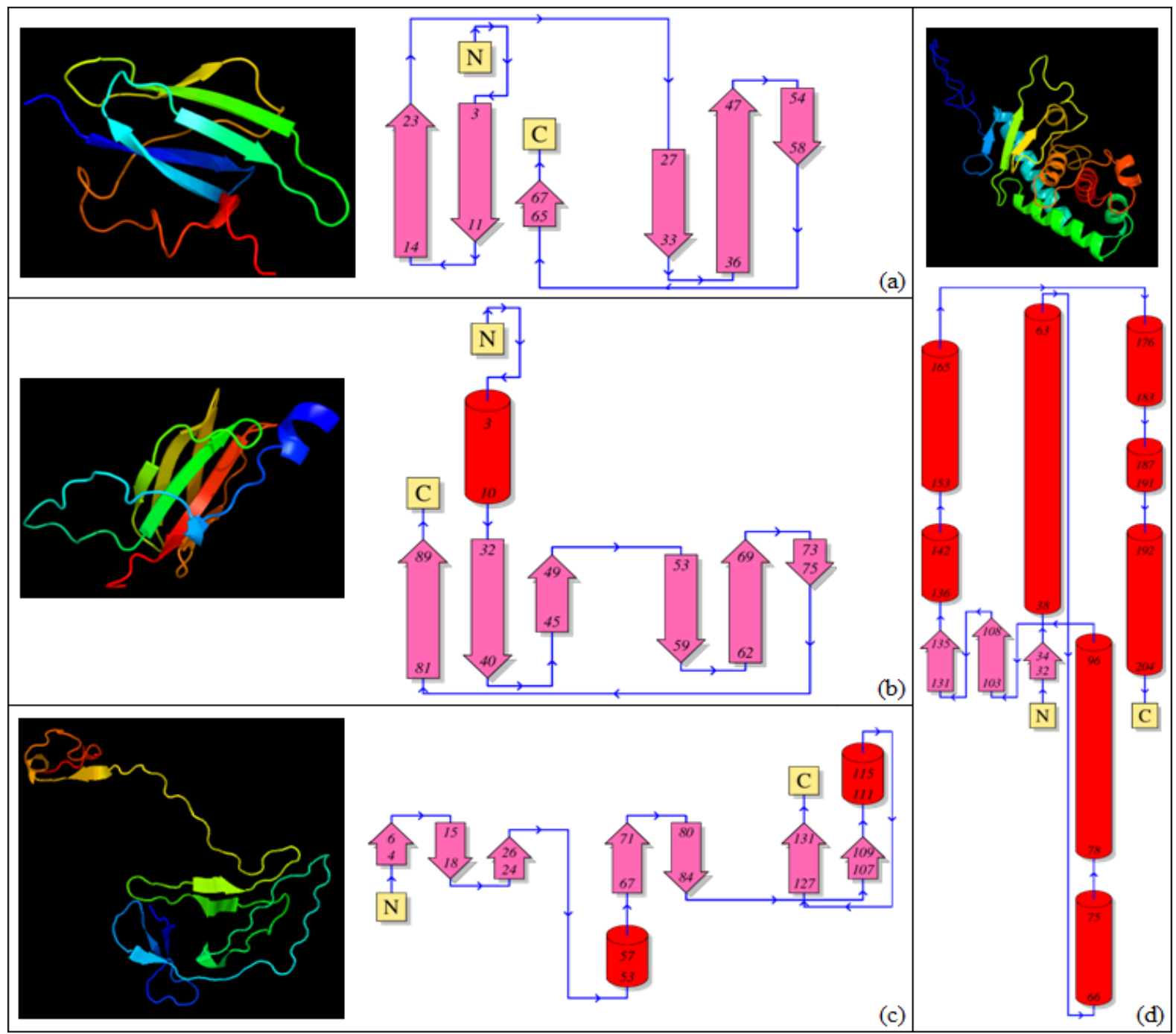

Figure 2. Three dimensional protein modeling and topology diagram of $A v r$ genes isolated from M. oryzae 7'. (a) AvrPiz-t, (b) AVR-Pik, (c) Avr-Pi54, and (d) AVR-Pital.

Table 3. High frequency motif detected in $A v r$ sequences.

\begin{tabular}{cccccc}
\hline Gene & $\begin{array}{c}\text { N-myristoylation } \\
\text { site }\end{array}$ & $\begin{array}{c}\text { Protein kinase C } \\
\text { phosphorylation } \\
\text { site }\end{array}$ & $\begin{array}{c}\text { Casein kinase II } \\
\text { phosphorylation } \\
\text { site }\end{array}$ & $\begin{array}{c}\text { N-glycosylation } \\
\text { site }\end{array}$ & $\begin{array}{c}\text { Amidation } \\
\text { site }\end{array}$ \\
\hline AvrPiz-t & $\checkmark$ & $\checkmark$ & $\checkmark$ & $\mathbf{x}$ & $\mathbf{x}$ \\
AVR-Pik & $\checkmark$ & $\checkmark$ & $\times$ & $\checkmark$ & $\checkmark$ \\
Avr-Pi54 & $\checkmark$ & $\mathbf{x}$ & $\checkmark$ & $\mathbf{x}$ & $\mathbf{\times}$ \\
AVR-Pital & $\checkmark$ & $\checkmark$ & $\checkmark$ & $\mathbf{x}$ & $\mathbf{x}$ \\
AvrPi9 & $\checkmark$ & $\checkmark$ & $\mathbf{x}$ & $\mathbf{x}$ & $\mathbf{x}$ \\
AVR-Pia & $\checkmark$ & $\checkmark$ & $\mathbf{x}$ & $\mathbf{x}$ & $\mathbf{x}$ \\
AVR-Pii & $\checkmark$ & $\mathbf{x}$ & $\checkmark$ & $\mathbf{x}$ & $\mathbf{x}$ \\
AvrPib & $\checkmark$ & $\mathbf{x}$ & $\checkmark$ & $\mathbf{x}$ & $\mathbf{x}$ \\
\hline
\end{tabular}


Table 4. Ramachandran plot statistics and stuctural neighbours of modeled AVR proteins.

\begin{tabular}{lcccc}
\hline & AvrPiz- $t$ & AVR-Pik & Avr-Pi54 & AVR-Pital \\
\hline Ramachandran plot statistics: & & & & \\
Number of residues in favoured region & $67(76.1 \%)$ & $86(95.6 \%)$ & $83(62.9 \%)$ & $181(88.3 \%)$ \\
Number of residues in allowed region & $13(14.8 \%)$ & $3(3.3 \%)$ & $19(14.4 \%)$ & $16(7.8 \%)$ \\
Number of residues in outlier region & $8(9.1 \%)$ & $1(1.1 \%)$ & $30(22.7 \%)$ & $8(3.9 \%)$ \\
\hline & 2MM0-A & 2MYV-A & 2MM0-A & 2X1G-A \\
Structural Neighbours & 2MM2-A & 2MM2-A & 1EB6-A \\
& 5A6W-C & 2LW6-A & \\
\hline
\end{tabular}

(PDB IDs and protein names of structural neighbours are as follow: 2MM0-A: Host-selective toxin protein; 2MM2-A: Toxb; 5A6W-C: AVR-Pik Protein; 2MYV-A: AVR1-CO39; 2LW6-A: AvrPiz-t protein; 2MYW-A: AVR-Pia protein; 2X3C-A: Extracellular Toxic Zinc Metalloendopeptidase; 1G12-A: Peptidyl-Lys Metalloendopeptidase; 1EB6-A: Neutral Protease II).

\section{DISCUSSION}

Occurrence of $M$. oryzae has been reported in Sarawak since several decades ago. However, this is the first study focusing specifically on $A v r$ genes of this rice blast fungus from local isolates. The successful molecular cloning of Avr genes has detected and confirmed their presence in the M. oryzae 7' of Sarawak isolates. The cloning involved full-length coding sequence and would provide useful information for subsequent functional and expression studies. However, the lacks of significant sequence similarity among $A v r$ genes under study complicate the efforts to identify components accounted for their functional similarity in triggering host defense. Understanding on the domains and motifs present in AVR effector proteins is important for their functional prediction.

AVR-Pital predicted under the M35 family has two signature zinc-binding histidines as well as a catalytic glutamate (Markaryan et al., 1994). Additionally, a motif encoding for zinc protease is detected, which may imply the function in metalloendopeptidase activity. Neutral metallopeptidase NMP1 has recently found to play a major role in mycotropic interactions and self defence of avirulent plant symbiont, Trichoderma species which is capable of producing compounds that induce resistance response in plants (Harman et al., 2004; Zhang et al., 2016).

The motif of N-myristoylation presents in all the eight analyzed sequences. Such appearance might give a clue on common biochemical activities performed by the $A v r$ genes. N-myristoylation, is one form of protein fatty acylation that serves as a targeting strategy between plants and pathogens (Boyle et al., 2016). Protein modification involving N-myristoylation occurs mainly on cytoplasmic proteins while rarely found on integral membrane proteins. They are usually involved in the regulation of cellular structure and function which encompassed proteins associated with cellular signal transduction pathways (Moriya et al., 2013). The importance of consensus myristoylation sites has been highlighted in ensuring efficient localization of AVR proteins and HR elicitation in different plants (Nimchuk et al., 2000; Tampakaki et al., 2002).

According to Devanna et al. (2014), the presence of phosphorylation site in a protein implied the role of the protein in signal transduction and transmittance to other genes for downstream activities. For example, Protein kinase C (PKC) phosphorylation sites having significant role in the regulation of catalytic activity, stability and intracellular localization of enzyme (Freeley et al., 2011). It has been noted that proteins, which possess this particular phosphorylation site, were highly expressed during appressorium formation in Magnaporthe species (Thines et al., 1998; Xue et al., 2002). The role of appressorium has long been noted as an infection cell employed by $M$. oryzae to invade rice plant upon maturation in the form of hyphae (Talbot \& Wilson, 2009). 
On the other hand, casein kinase II (CK2) activity mediates signal responsible for virulence in a fungal plant pathogen, Cryphonectria parasitica in which the elimination of CK2 phosphorylation site lead to a lack of virulence (Salamon et al., 2010). Apart from that, glycosylation regulates how proteins fold, their biological activity as well as their half-life (Kotz et al., 2010). Study shown that Slp1 effector protein from $M$. oryzae undergo $\mathrm{N}$-glycosylation is capable of evading plant immune response (Chen et al, 2014).

A novel motif is detected in AvrPiz- $t$ gene isolated from local $M$. oryzae isolate. The motif is located at gene region coding for signal peptide. Signal peptide carries the information that direct targeting and translocation of secretory and membrane proteins. Translocation of AVR proteins into host cells could be performed on the basis of intracellular recognition by the host resistance proteins signaled by their $\mathrm{N}$-terminal regions in the absence of the pathogen itself (Rafiqi et al., 2010).

Li et al. (2009) has revealed the importance of the secretion signal at the $\mathrm{N}$ terminus of AvrPiz- $t$ in triggering host immune response mediated by Piz- $t$, whereby the removal of secretion signal caused the loss of function in the avirulent phenotype. This indicated information carried in signal peptide is vital for recognition by cognate resistance gene in the host plant and therefore the lack of pathogenicity. Finding of the motif in these four $A v r$ genes might be useful in further study on plant-pathogen recognition mechanism and in the sequence pattern of effector proteins. Thus, functional significance of this motif in the regulation and expression of AvrPiz-t, AvrPi9, AVR-Pia, and AVR-Pii has to be validated and characterized experimentally.

AvrPiz- $t$ to as structural neighbour of $A V R$ $P i k$, at a z-score of $>2.0$ implying the significance in structural similarity. Previous study supported by experimental data showing that AvrPiz-t, AVR-Pia from M. oryzae, AVR1CO39 from $M$. grisea, and ToxB from Pyrenophora tritici-repentis are sequenceunrelated structural homologs having a common $\beta$-sandwich structure and similar topology was suggested to be categorized under family MAX-effectors (Magnaporthe Avrs and ToxB like) (Zhang et al., 2013; Nyarko et al., 2014; de Guillen et al., 2015). Notably, separate study by Maqbool et al. (2015) also reported the presence of characteristic $\beta$-sandwich structure of MAXeffectors family in $A V R$-PikD from M. oryzae. Thus, this is consistent with findings of study whereby the predicted 3D structure of AvrPiz- $t$ and $A V R$-Pik have the $\beta$-sandwich structure and structural similarity validated by the Dali z-score of 3.7.

Each of this MAX-effectors function in recognition to NLR (nucleotide-binding leucine-rich repeat) immune receptors in host rice plant: AvrPiz- $t$ to Piz- $t$ by indirect interaction, $A V R-P i k$ to $P i k$ by direct binding, as well as AVRI-CO39 and AVR-Pia to the same RGA4/RGA5 by direct binding (Cesari et al., 2013; Maqbool et al., 2015; Park et al., 2016). NLR proteins are the largest class of $R$ genes that play the key role as receptors that function in recognition to the pathogenic secreted effector proteins. Upon recognition between the plant effector proteins and pathogen effector proteins, HR associated with local cell death is triggered to avoid further spread of disease caused by the pathogen (Jones \& Dangl, 2006).

\section{CONCLUSION}

In conclusion, several $A v r$ genes were isolated in this study which were AvrPiz-t, AVR-Pik, $A v r$-Pi54, and AVR-Pital. Further structural studies have been conducted based on the ORF of these genes, which a novel signal peptide motif was found in AvrPiz-t. This study serves as an approach to fill up the knowledge gap on the distribution and variation of $A v r$ gene. The discovery of these genes in $M$. oryzae 7' implied their possible presence in other closely related $M$. oryzae isolates. Further study in this gene to include more isolates would enhance understanding in $A v r$ gene sequence diversity. In a wider prospect, there is a need to investigate the presence and dynamics of their cognate resistance gene in rice plant which would provide useful information on selection pressure characterizing the $A v r$ gene profile of M. oryzae. 


\section{ACKNOWLEDGEMENTS}

This work was funded by FRGS/SG05(03)/1148/2014(15) and RAGS/ WAB01(1)/1319/2015(13). The authors would like to acknowledge the Agriculture Research Centre, Semonggok for supplying the culture of Magnaporthe oryzae 7'.

\section{REFERENCES}

Agrios, G.N. (2005). Plant pathology. Fifth Edition. Burlington, MA: Elsevier Academic Press.

Altschul, S.F., Madden, T.L., Schäffer, A.A., Zhang, J., Zhang, Z., Miller, W. \& Lipman, D. J. (1997). Gapped BLAST and PSIBLAST: A new generation of protein database search programs. Nucleic Acids Research, 25(17): 3389-3402.

Artimo, P., Jonnalagedda, M., Arnold, K., Baratin, D., Csardi, G., de Castro, E., Duvaud, S., Flegel, V., Fortier, A., Gasteiger, E., Grosdidier, A., Hernandez, C., Ioannidis, V., Kuznetsov, D., Liechti, R., Moretti, S., Mostaguir, K., Redaschi, N., Rossier, G., Xenarios, I., \& Stockinger, H. (2012). ExPASy: SIB bioinformatics resource portal. Nucleic Acids Research, 40 (W1): W597-W603.

Bailey, T.L. \& Elkan, C. (1994). Fitting a mixture model by expectation maximization to discover motifs in biopolymers. In Altman, R., Brutlag, D., Karp, P., Lathrop, R. \& Searls, D. (Eds.), Proceedings of the Second International Conference on Intelligent Systems for Molecular Biology. Menlo Park, CA: AAAI Press. Pp 28-36.

Boyle, P.C., Schwizer, S., Hind, S.R., Kraus, C. M., De la Torre Diaz, S., He, B. \& Martin, G.B. (2016). Detecting N-myristoylation and S-acylation of host and pathogen proteins in plants using click chemistry. Plant Methods, 12 (1): 38.

Cesari, S., Thilliez, G., Ribot, C., Chalvon, V., Michel, C., Jauneau, A., Rivas, S., Alaux, L., Kanzaki, H., Okuyama, Y., Morel, J.B., Fournier, E., Tharreau, D., Terauchi, R. \& Kroj, T. (2013). The rice resistance protein pair RGA4/RGA5 recognizes the Magnaporthe oryzae effectors AVR-Pia and
AVR1-CO39 by direct binding. The Plant Cell, 25(4): 1463-1481.

Chen, X.L., Shi, T., Yang, J., Shi, W., Gao, X., Chen, D., Xu, X., Xu, J.R., Talbot, N.J. \& Peng, Y. -L. (2014). N-glycosylation of effector proteins by an a-1, 3mannosyltransferase is required for the rice blast fungus to evade host innate immunity. The Plant Cell, 26(3): 1360-1376.

de Castro, E., Sigrist, C.J.A., Gattiker, A., Bulliard, V., Langendijk-Genevaux, P.S., Gasteiger, E., Bairoch, A. \& Hulo, N. (2006). ScanProsite: Detection of PROSITE signature matches and ProRule-associated functional and structural residues in proteins. Nucleic Acids Research, 34: W362W365.

de Guillen, K., Ortiz-Vallejo, D., Gracy, J., Fournier, E., Kroj, T. \& Padilla, A. (2015). Structure analysis uncovers a highly diverse but structurally conserved effector family in phytopathogenic fungi. PLoS Pathogens, 11 (10): e1005228.

Devanna, N.B., Vijayan, J. \& Sharma, T.R. (2014). The blast resistance gene Pi54 of cloned from Oryza officinalis interacts with $A v r-P i 54$ through Its novel non-LRR domains. PLoS One, 9(8): e104840.

Fatah, T., Rafii, M.Y., Rahim, H.A., Meon, S., Azhar, M. \& Latif, M. A. (2014). Cloning and analysis of QTL linked to blast disease resistance in Malaysian rice variety Pongsu Seribu 2. International Journal of Agriculture \& Biology, 16(2): 395-400.

Food and Agriculture Organization of the United Nations (2002). FAO Rice Information, Volume 3. Rome, Italy: FAO.

Freeley, M., Kelleher, D. \& Long, A. (2011). Regulation of protein kinase $C$ function by phosphorylation on conserved and nonconserved sites. Cellular Signaling, 23(5): 753-762.

Gasteiger, E., Hoogland, C., Gattiker, A., Duvaud, S., Wilkins, M.R., Appel, R.D. \& Bairoch, A. (2005). Protein identification and analysis tools on the ExPASy server. In Walker, J.M. (Ed.), The Proteomics Protocols Handbook, 1st edition. Totowa, NJ: Humana Press. Pp. 571-607. 
Harman, G.E., Howell, C.R., Viterbo, A., Chet, I. \& Lorito, M. (2004). Trichoderma species--opportunistic, avirulent plant symbionts. Nature Reviews Microbiology, 2(1): 43-56.

Holm, L. \& Laakso, L. M. (2016). Dali server update. Nucleic Acids Research, 44 (W1): W351-W355.

Horbach, R., Navarro-Quesada, A.R., Knoggec, W. \& Deising, H.B. (2011). When and how to kill a plant cell: Infection strategies of plant pathogenic fungi. Journal of Plant Physiology, 168(1): 51-62.

Jones, J.D.G. \& Dangl, J.L. (2006). The plant immune system. Nature, 444: 323-329.

Jones, P., Binns, D., Chang, H.Y., Fraser, M., Li, W., McAnulla, C., McWilliam, H., Maslen, J., Mitchell, A., Nuka, G., Pesseat, S., Quinn, A.F., Sangrador-Vegas, A., Scheremetjew, M., Yong, S.Y., Lopez, R. \& Hunter, S. (2014). InterProScan 5: Genomescale protein function classification. Bioinformatics, 30(9): 1236-1240.

Joosten, M.H.A.J., Honée, G., van Kan, J.A. L. \& de Wit, P.J.G.M. (1997). The gene-forgene concept in plant-pathogen interactions: Tomato-Cladosporium fulvum. In Carrroll, G.C. \& Tudzynski, P. (Eds.), The mycota $V$. Plant relationships Part $b$. Berlin, Germany: Springer-Verlag. Pp 3-16.

Kelley, L.A., Mezulis, S., Yates, C.M., Wass, M.N. \& Sternberg, M.J. (2015). The Phyre2 web portal for protein modeling, prediction and analysis. Nature Protocols, 10(6): 845858.

Kibbe, W.A. (2007). OligoCalc: an online oligonucleotide properties calculator. Nucleic Acids Research, 35: W43-W46.

Kotz, A., Wagener, J., Engel, J., Routier, F.H., Echtenacher, B., Jacobsen, I., Heesemann, J. \& Ebel, F. (2010). Approaching the secrets of N-glycosylation in Aspergillus fumigatus: Characterization of the AfOch1 protein. PLoS One, 5(12): e15729.

Lamb, C.J. (1994). Plant disease resistance genes in signal perception and transduction. Cell, 76: 419-422.
Laskowski, R.A., Watson, J.D. \& Thornton, J.M. (2005). ProFunc: A server for predicting protein function from 3D structure. Nucleic Acids Research, 33 (suppl 2): W89-W93.

Li, W., Wang, B., Wu, J., Lu, G., Hu, Y., Zhang, X., Zhang, Z., Zhao, Q., Feng, Q., Zhang, H., Wang, Z., Wang, G-L., Han, B., Wang, Z. \& Zhou, B. (2009). The Magnaporthe oryzae avirulence gene AvrPiz- $t$ encodes a predicted secreted protein that triggers the immunity in rice mediated by the blast resistance gene Piz-t. Molecular Plant-Microbe Interactions Journal, 22(4): 411-420.

Lovell, S.C., Davis, I.W., Arendall III, W.B., de Bakker, P.I.W., Michael Word, J., Prisant, M.G., Richardson, J.S. \& Richardson, D.C. (2002). Structure validation by Calpha geometry: phi, psi and Cbeta deviation. Proteins: Structure, Function \& Genetics, 50(3): 437-450.

Marchler-Bauer, A., Derbyshire, M.K., Gonzales, N.R., Lu, S., Chitsaz, F., Geer, L. Y., Geer, R.C., He, J., Gwadz, M., Hurwitz, D.I., Lanczycki, C.J., Lu, F., Marchler, G.H., Song, J.S., Thanki, N., Wang, Z., Yamashita, R.A., Zhang, D., Zheng, C. \& Bryant, S.H. (2015). CDD: NCBI's conserved domain database. Nucleic Acids Research, 43(D1): D222-D226.

Markaryan, A., Morozova, I., Yu, H. \& Kolattukudy, P.E. (1994). Purification and characterization of an elastinolytic metalloprotease from Aspergillus fumigatus and immunoelectron microscopic evidence of secretion of this enzyme by the fungus invading the murine lung. Infection and Immunity, 62(6): 2149-2157.

Maqbool, A., Saitoh, H., Franceschetti, M., Stevenson, C.E.M., Uemura, A., Kanzaki, H., Kamoun, S., Terauchi, R. \& Banfield, M.J. (2015). Structural basis of pathogen recognition by an integrated HMA domain in a plant NLR immune receptor. eLife, 4: $\mathrm{e} 08709$.

Martin, K.J. \& Rygiewicz, P.T. (2005). Fungalspecific PCR primers developed for analysis of the ITS region of environmental DNA extracts. BMC Microbiology, 5:28. 
Miki, S., Matsui, K., Kito, H., Otsuka, K., Ashizawa, T., Yasuda, N., Fukiya, S., Sato, J., Hirayae, K., Fujita, Y., Nakajima, T., Tomita, F. \& Sone, T. (2009). Molecular cloning and characterization of the AVR-Pia locus from a Japanese field isolate of Magnaporthe oryzae. Molecular Plant Pathology, 10(3): 361-374.

Moriya, K., Nagatoshi, K., Noriyasu, Y., Okamura, T., Takamitsu, E., Suzuki, T. \& Utsumi, T. (2013). Protein $N$-myristoylation plays a critical role in the endoplasmic reticulum morphological change induced by overexpression of protein Lunapark, an integral membrane protein of the endoplasmic reticulum. PLoS One, 8(11): e78235.

Nimchuk, Z., Marois, E., Kjemtrup, S., Leister, R.T., Katagiri, F. \& Dangl, J.L. (2000). Eukaryotic fatty acylation drives plasma membrane targeting and enhances function of several type III effector proteins from Pseudomonas syringae. Cell, 101(4): 353363.

Nyarko, A., Singarapu, K.K., Figueroa, M., Manning, V.A., Pandelova, I., Wolpert, T. J., Ciuffetti, L.M. \& Barbar, E. (2014). Solution NMR structures of Pyrenophora tritici-repentis ToxB and its inactive homolog reveal potential determinants of toxin activity. The Journal of Biological Chemistry, 289: 25946-25956.

Orbach, M.J., Farrall, L., Sweigard, J.A., Chumley, F.G. \& Valent, B. (2000). A telomeric avirulence gene determines efficacy for the rice blast resistance gene $P i$ ta. The Plant Cell, 12(11): 2019-2032.

Park, C.H., Shirsekar, G., Bellizzi, M., Chen, S., Songkumarn, P., Xie, X., Shi, X., Ning, Y., Zhou, B., Suttiviriya, P., Wang, M., Umemura, K. \& Wang, G. -L. (2016). The E3 ligase APIP10 connects the effector AvrPiz-t to the NLR receptor Piz-t in rice. PLoS Pathogens, 12(3): e1005529.

Petersen, T.N., Brunak, S., von Heijne, G. \& Nielsen, H. (2011). SignalP 4.0: discriminating signal peptides from transmemberane regions. Nature Methods, 8: 785-786.
Rafiqi, M., Gan, P.H.P., Ravensdale, M., Lawrence, G.J., Ellis, J.G., Jones, D.A., Hardham, A.R. \& Dodds, P.N. (2010). Internalization of flax rust avirulence proteins into flax and tobacco cells can occur in the absence of the pathogen. The Plant Cell, 22(6): 2017-2032.

Ray, S., Singh, P. K., Gupta, D. K., Mahato, A. K., Sarkar, C., Rathour, R., Singh, N.K. \& Sharma, T.R. (2016). Analysis of Magnaporthe oryzae genome reveals a fungal effector, which is able to induce resistance response in transgenic rice line containing resistance gene, Pi54. Frontiers in Plant Science, 7: 1140.

Ribot, C., Césari, S., Abidi, I., Chalvon, V., Bournaud, C., Vallet, J., Lebrun, M.H., Morel, J.B. \& Kroj, T. (2013). The Magnaporthe oryzae effector AVR1-CO39 is translocated into rice cells independently of a fungal-derived machinery. The Plant Journal, 74(1): 1-12.

Salamon, J.A., Acuña, R. \& Dawe, A. L. (2010). Phosphorylation of phosducin-like protein BDM-1 by protein kinase 2 (CK2) is required for virulence and $\mathrm{G} \beta$ subunit stability in the fungal plant pathogen Cryphonectria parasitica. Molecular Microbiology, 76(4): 848-860.

Sievers, F., Wilm, A., Dineen, D., Gibson, T. J., Karplus, K., Li, W., Lopez, R., McWilliam, H., Remmert, M., Söding, J., Thompson, J.D. \& Higgins, D.G. (2011). Fast, scalable generation of high-quality protein multiple sequence alignments using Clustal Omega. Molecular Systems Biology, 7: 539.

Sweigard, J.A., Carroll, A.M., Kang, S., Farrall, L., Chumley, F.G. \& Valent, B. (1995). Identification, cloning, and characterization of $P W L 2$, a gene for host species specificity in the rice blast fungus. The Plant Cell, 7(8): 1221-1233.

Talbot, N.J. \& Wilson, R.A. (2009). Under pressure: Investigating the biology of plant infection by Magnaporthe oryza. Nature Reviews Microbiology, 7(3): 185-195.

Tampakaki, A.P., Bastaki, M., Mansfield, J.W. \& Panopoulos, N.J. (2002). Molecular determinants required for the avirulence function of $A v r P p h B$ in bean and other 
plants. Molecular Plant-Microbe Interactions, 15(3): 292-300.

Tamura, K., Stecher, G., Peterson, D., Filipski, A. \& Kumar, S. (2013). MEGA6: Molecular Evolutionary Genetics Analysis Version 6.0. Molecular Biology and Evolution, 30(12): 2725-2729.

Tanweer, F.A., Rafii, M.Y., Sijam, K., Rahim, H.A., Ahmed, F., Latif, M.A. \& Ashkani, S. (2015). Cloning and characterization of two major blast resistance genes $P i-b$ and $P i-k h$ from Malaysian rice variety Pongsu Seribu 2. Plant Omics Journal, 8(3): 257-263.

Thines, E., Eilbert, F., Sterner, O. \& Anke, H. (1998). Inhibitors of appressorium formation in Magnaporthe grisea: A new approach to control rice blast disease. Pest Management Science, 54(3): 314-316.

Untergasser, A., Nijveen, H., Rao, X., Bisseling, T., Geurts, R. \& Leunissen, J.A. M. (2007). Primer3Plus, an enhanced web interface to Primer3. Nucleic Acids Research, 35(suppl_2): W71-W74.

Valera, H.G.A. \& Lee, J. (2016). Do rice prices follow a random walk? Evidence from Markov switching unit root tests for Asian markets. Agricultural Economics, 47(6):683-695.

Wu, J., Kou, Y., Bao, J., Li, Y., Tang, M., Zhu, X., Ponaya, A., Xiao, G., Li, J., Li, C., Song, M.Y., Cumagun, C.J.R., Deng, Q., Lu, G., Jeon, J.S., Naqvi, N. \& Zhou, B. (2015). Comparative genomics identifies the Magnaporthe oryzae avirulence effector AvrPi9 that triggers $\mathrm{Pi} 9$-mediated blast resistance in rice. New Phytologist, 206(4): 1463-1475.
Xue, C., Park, G., Choi, W., Zheng, L., Dean, R.A. \& Xua, J. (2002). Two novel fungal virulence genes specifically expressed in appressoria of the rice blast fungus. The Plant Cell, 14(9): 1-13.

Yoshida, K., Saitoh, H., Fujisawa, S., Kanzaki, H., Matsumura, H., Yoshida, K., Tosa, Y., Chuma, I., Tokano, Y., Win, J., Kamoun, S. \& Terauchi, R. (2009). Association genetics reveals three novel avirulence genes from the rice blast fungal pathogen Magnaporthe oryzae. The Plant Cell, 21(5): 1573-1591.

Yu, C-S., Chen, Y.-C., Lu, C.-H. \& Hwang, JK. (2006). Prediction of protein subcellular localization. Proteins: Structure, Function and Bioinformatics, 64(3): 643-651.

Zhang, J., Bayram Akcapinar, G., Atanasova, L., Rahimi, M.J., Przylucka, A., Yang, D., Kubicek, C. P., Zhang, R., Shen, Q. \& Druzhinina, I.S. (2016). The neutral metallopeptidase NMP1 of Trichoderma guizhouense is required for mycotrophy and self-defence. Environmental Microbiology, 18(2): 580-597.

Zhang, S., Wang, L., Wu, W., He, L., Yang, X. \& Pan, Q. (2015). Function and evolution of Magnaporthe oryzae avirulence gene AvrPib responding to the rice blast resistance gene Pib. Scientific Reports, 5: 11642.

Zhang, Z. M., Zhang, X., Zhou, Z.R., Hu, H. Y., Liu, M., Zhou, B. \& Zhou, J. (2013). Solution structure of the Magnaporthe oryzae avirulence protein AvrPiz-t. Journal of Biomolecular NMR, 55: 219-223. 